Canadian Science Publishing

Journal of Unmanned Vehicle Systems Revue des systèmes de véhicules télécommandés

\title{
Photogrammetry of killer whales using a small hexacopter launched at sea
}

\begin{tabular}{|r|l|}
\hline Journal: & Journal of Unmanned Vehicle Systems \\
\hline Manuscript ID & juvs-2015-0020.R1 \\
\hline Manuscript Type: & Note \\
\hline Complete List of Authors: & $\begin{array}{l}\text { Durban, J.W.; National Marine Fisheries Service, NOAA, Southwest } \\
\text { Fisheries Science Center } \\
\text { Fearnbach, H.; National Marine Fisheries Service, NOAA, Southwest } \\
\text { Fisheries Science Center } \\
\text { Barrett-Lennard, L.G.; Vancouver Aquarium Marine Science Center, } \\
\text { Perryman, W.L.; National Marine Fisheries Service, NOAA, Southwest } \\
\text { Fisheries Science Center } \\
\text { LeRoi, D.J.; Aerial Imaging Solutions, }\end{array}$ \\
\hline Keyword: & \begin{tabular}{l} 
UAS, Hexacopter, Wildlife, VTOL, Whales \\
\hline
\end{tabular} \\
\hline
\end{tabular}




\section{Photogrammetry of killer whales using a small hexacopter launched at sea}

4 Durban, J.W. ${ }^{1}$, Fearnbach, H. ${ }^{1}$, Barrett-Lennard, L.G. ${ }^{2}$, Perryman, W.L. ${ }^{1}$, LeRoi, D.J. ${ }^{3}$

5

$6 \quad{ }^{1}$ Southwest Fisheries Science Center, National Marine Fisheries Service, NOAA; 8901 La Jolla

$7 \quad$ Shores Drive, La Jolla, CA 92037, U.S.A; John.Durban@noaa.gov

$8{ }^{2}$ Vancouver Aquarium Marine Science Center, 845 Avison Way, Vancouver, BC, VG63E2,

9 Canada

$10{ }^{3}$ Aerial Imaging Solutions, 5 Myrica Way, Old Lyme, CT 06371, U.S.A.

11

12

13

14

15

16

17

18

19

20

21

22

23 


\section{Abstract}

2 Conventional aircraft have been used for photogrammetry studies of free-ranging whales,

3 but are often not practical in remote regions or not affordable. Here we report on the use of a

4 small, unmanned hexacopter (APH-22; Aerial Imaging Solutions) as an alternative method for

5 collecting photographs to measure killer whales (Orcinus orca) at sea. We deployed and

6 retrieved the hexacopter by hand during 60 flights (average duration 13.2 minutes, $\max =15.7$ )

7 from the upper deck of an $8.2 \mathrm{~m}$ boat, utilizing the aircraft's vertical takeoff and landing (VTOL)

8 capability. The hexacopter was quiet and stable in flight, and therefore could be flown at

9 relatively low altitudes without disturbing whales. The payload was a Micro Four-Thirds system

10 camera that was used to obtain 18,920 still images from an altitude of $35-40 \mathrm{~m}$ above the whales.

11 Tests indicated a ground-resolved distance of $<1.4 \mathrm{~cm}$ across the full extent of a flat and

12 undistorted field of view, and an onboard pressure altimeter enabled measurements in pixels to

13 be scaled to true size with an average accuracy of $5 \mathrm{~cm}$. As a result, the images were sharp

14 enough to differentiate individual whales using natural markings (77 whales in total) and

15 preliminary estimates resolved differences in whale lengths ranging from $2.6 \mathrm{~m}$ to $5.8 \mathrm{~m}$. This first

16 application at sea demonstrated the APH-22 hexacopter to be a safe and cost-effective platform

17 for collecting photogrammetry images to fill key scientific data gaps about whales, and we

18 anticipate this utility will extend to studies of other wildlife species.

20 Keywords: UAS, Hexacopter, Wildlife VTOL, Whales 
Conventional aircraft have been successfully used for photogrammetry studies of free-

2 ranging whales. Fixed-wing planes and helicopters have been used to obtain vertical photographs

3 from directly above whales, from which shape profiles can be measured to assess body condition

4 to infer nutritional status and pregnancy (e.g. Perryman and Lynn 2002). When combined with

5 information on scale (= altitude / focal length), these images can also be used to estimate

6 absolute length (e.g. Pitman et al. 2007) and monitor growth trends (e.g. Fearnbach et al. 2011).

7 However, aircraft operations are often not practical in remote regions, and not affordable under

8 typical research budgets, and therefore this technique has not been widely used.

9 Here we report on a recent project using a small Unmanned Aerial System (UAS) as an

10 alternative method for successfully obtaining photogrammetry images of killer whales (Orcinus

11 orca) at sea. Our study area was around Vancouver Island, off the British Columbia coastline of

12 western Canada. Previously, we used a helicopter to measure "Southern Resident" killer whales

13 in the more accessible waters off Southern Vancouver Island (Fearnbach et al. 2011), but

14 required an alternative approach to obtain comparative measurements from the "Northern

15 Resident" population in the more remote area at the north of the island. We chose to use a small

16 multi-rotor UAS because vertical takeoff and landing (VTOL) capability was required to operate

17 from a small boat, and we required stability in flight for photographic operations. We chose a

18 small (1.2kg dry weight without payload; $82 \mathrm{~cm}$ wingspan) hexacopter that was recently used in

19 Antarctica to obtain photographs for counting seals and penguins, and to estimate the size of

20 leopard seals onshore (Goebel et al. 2015). This UAS platform has been proven to have the

21 endurance and performance characteristics to conduct successful photographic missions in a

22 windy environment, and to create a limited sound footprint that does not disturb wildlife. 
The APH-22 hexacopter (Aerial Imaging Solutions, Old Lyme, CT; Figure 1) is

2 described in Goebel et al. (2015). However, one key modification to firmware was required for

3 operating from a boat, namely the ability to store a motionless calibration of the gyro sensors

4 made on land and recall these gyro offsets from non-volatile memory when on the boat. This

5 enabled the hexacopter to maintain stable flight attitude, even when launched from a moving

6 platform at sea. We successfully deployed and retrieved the hexacopter by hand during 60 flight

7 missions launched from the upper deck of an 8.2m SeaSport boat (Figure 2). This procedure

8 proved to be safe and repeatable, due to the stable flight and low weight of the hexacopter; the

9 only payload was a camera (Olympus E-PM2, 0.23kg; Olympus M.Zuiko 25mm F1.8 lens,

$10 \quad 0.13 \mathrm{~kg}$ ) and hexacopter battery (QuadroPower 6200mAh Lipo Flat; 0.58kg). Wind speeds were

11 less than $5 \mathrm{~m} / \mathrm{s}$ (10 knots) during all flights, as we chose to only fly when a smooth sea state

12 would enable detailed images of whales beneath the surface.

13 The average duration of the 60 flights was 13.2 minutes ( $\max =15.7$ mins). These marine

14 flights were conservatively ended well in advance of battery limitations - the APH-22 has been

15 flown for $>25$ minutes during test flights with the same battery. The total distance covered during

16 a flight averaged $1350 \mathrm{~m}(\max =2480 \mathrm{~m})$, but the distance to the pilot was less (typically $<200 \mathrm{~m})$

17 as the boat was continuously maneuvered to enable line-of site piloting of the hexacopter and

18 facilitate positioning over whales. The hexacopter was controlled by the pilot using a radio link

19 (2.4Ghz), and we did not experience any loss of link during the 13.25 hours of total flying. Finer-

20 scale positioning of the hexacopter above whales was accomplished through guidance from a

21 ground station operator who viewed live analog video captured by the onboard camera and

22 transmitted to a portable monitor on the boat using a 5.8Ghz link. When whales were in the

23 frame, the pilot used a remote link to trigger the capture of high-resolution (12.3MP) still images 
1 on the camera's flash memory. The ground station also displayed telemetry information

2 (910MHz link) which enabled monitoring of altitude, flight time and battery levels for flight

3 management.

4 We were successful at positioning the hexacopter directly above groups of killer whales,

5 and obtained a total of 18,920 still images from an altitude of $35-40 \mathrm{~m}$. We did not observe any

6 behavioral responses from the whales during any of the flights, and they likely were not aware of

7 the small hexacopter at these altitudes. The $25 \mathrm{~mm}$ lens we used is considered "normal" for the

8 Micro Four-Thirds sensor of the E-PM2 camera, in that the focal length is equal to the diagonal

9 of a square formed by the long dimension of the sensor, and therefore photogrammetry

10 measurements were possible across the full extent of a flat and undistorted field of view.

11 Previous resolution tests over a standard medium contrast (8:1) resolution target (RST-704,

12 series $\mathrm{C}$ ) showed that we had a ground-resolved distance of $<1.8 \mathrm{~cm}$ using the $25 \mathrm{~mm}$ lens at an

13 altitude of $50 \mathrm{~m}$, which improved further to $<1.4 \mathrm{~cm}$ at our standard altitude of $35 \mathrm{~m}$. Our images

14 of the whales clearly showed that this expected resolution was realized in photographs at sea:

15 notably, we could resolve differences in natural markings in order to identify individual whales

16 using images of their saddle patch pigmentation (Figure 3), which allowed us to link

17 measurements to whales of known age and sex (e.g. Fearnbach et al. 2011).

18 One of the key requirements of our photogrammetry system is the ability to obtain whale

19 length and width profiles on a real scale. Measurements from the images in pixels can be

20 converted to a true measurement using the known longitudinal dimension of the camera sensor

21 and the number of pixels comprising this known width, and these can then be scaled to true

22 lengths using the measured altitude and the focal length of the lens (e.g. Fearnbach et al. 2011).

23 The flight controllers on the hexacopter used a Freescale MPX4115A absolute air pressure 
1 sensor, which has on-chip temperature compensation, for altitude measurements. We calculated

2 the altitude of the hexacopter at 1-second intervals by applying the standard altitude equation to

3 the difference between the pressure while flying and the pressure at takeoff, with a known

4 takeoff height above sea level.

5 Onboard measures of altitude were validated by scale calculations of the distance

6 between points of known separation $(6.4 \mathrm{~m}=$ approximate whale length) on the deck of our

7 research vessel, measured from photographs taken at our standard photogrammetry altitudes.

8 Using 16 different calibration photographs from calculated altitudes of $35-38 \mathrm{~m}$, the average bias

9 was $-0.05 \mathrm{~m}$ (standard deviation $=0.29 \mathrm{~m}$ ), representing $<1 \%$ of the total length of the boat. This

10 indicated the ability to monitor absolute size and growth of whales with precision, which is

11 demonstrated in Figure 4 by estimated length differences among seven whales of varying ages

12 within the "I16 matriline" (family group) of killer whales. These whales ranged in ages between

13 a first year calf and a 45yr old adult female at the time of the photograph in 2014, with estimated

14 lengths ranging from $2.6 \mathrm{~m}$ to $5.8 \mathrm{~m}$ from this particular image. At the time of writing, work is

15 underway to identify and measure all the whales in this large photographic sample, and further

16 data collection is planned to quantitatively monitor individual whale growth and body condition

17 into the future.

18 This first, and very successful, field effort at sea has demonstrated the APH-22

19 hexacopter to have great utility for collecting photogrammetry images to fill key scientific data

20 gaps about free ranging whales. It is a small and portable aircraft with VTOL capability that

21 enables safe deployment and retrieval from even small boat platforms, and therefore enables

22 aerial photogrammetry in remote locations where conventional aircraft are impractical. It is quiet

23 and stable in flight, and can therefore be flown at relatively low altitudes without disturbing 
1 whales. As a result, we can obtain high-resolution images that are sharp enough to differentiate

2 individual whales using natural markings, with precise altitude to enable quantitative

3 measurements. We anticipate that these advantageous features will provide a cost-effective

4 option for studies of wildlife populations in general, not just whales.

\section{Acknowledgements}

7 Hexacopter flights were authorized by a Special Flight Operations Certificate from Transport

8 Canada and approaches to whales by both the boat and hexacopter were authorized by Research

9 License issued by Fisheries and Oceans Canada (2014-5 SARA-327). Jim Borrowman helped

10 with field logistics, Cara Crossman facilitated project planning and Jared Towers assisted with

11 identifying known whales from aerial images. Field costs were supported by a grant from the

12 Seaworld \& Busch Gardens Conservation Fund. Development of the hexacopter was performed

13 under a grant from NOAA's Office of Marine and Aviation Operations, and through the support

14 of Commander Michael J. Silah, NOAA.

\section{References}

17 Ellis, G.M., Towers, J.R., and Ford, J.K. 2011. Northern resident killer whales of British Columbia:

18 photo-identification catalogue and population status to 2010. Fisheries and Oceans Canada,

19 Science Branch, Pacific Region.

20 Fearnbach, H., Durban, J. W., Ellifrit, D. K., \& Balcomb III, K. C. 2011. Size and long-term growth

21 trends of endangered fish-eating killer whales. Endang. Species Res. 13: 173-180. 
1 Goebel, M.E., Perryman, W.L., Hinke, J.T., Krause, D.J., Hann, N.A., Gardner, S., and LeRoi, D.J.

2 2015. A small unmanned aerial system for estimating abundance and size of Antarctic predators

3 [online]. Polar Biol. doi:10.1007/s00300-014-1625-4.

4 Perryman, W.L. and Lynn, M.S. 2002. Evaluation of nutritive condition and reproductive status of

5 migrating gray whales (Eschrichtius robustus) based on analysis of photogrammetric data. J.

$6 \quad$ Cet. Res. Manage. 4: 155-164

7 Pitman, R.L., Perryman, W.L., LeRoi, D., and Eilers, E. 2007. A dwarf form of killer whale in

$8 \quad$ Antarctica. J. Mammal. 88: 43-48.

9

10

11

12

13

14

15

16

17

18

19

20

21

22

23

24

https://mc06.manuscriptcentral.com/juvs-pubs 
3 Figure 1: The APH-22 hexacopter (Aerial Imaging Solutions, Old Lyme, CT) that was used to

4 fly 60 successful missions to collect vertical photogrammetry images of killer whales at sea.

5 Here shown with the Olympus E-PM2 camera and interchangeable lens system; the camera

6 mounts on the underside of the hexacopter to be downward-facing.

8 Figure 2: Boat-based operations using the APH-22 hexacopter, which was hand-deployed and

9 retrieved (left, photo by Bruce Paterson) from the upper deck of an $8.2 \mathrm{~m}$ boat, and used to obtain

10 overhead images of killer whales from altitudes of 35-40m (right, photo by Suzanne Burns; red

11 arrow indicates the hexacopter above a killer whale).

13 Figure 3: Overhead image of a killer whale group (left) taken using an Olympus E-PM2 camera

14 mounted on the APH-22 hexacopter, with a zoomed insert (right) showing the distinct

15 pigmentation pattern of a whale's saddle patch that can be used to identify distinct individuals

16 (e.g. Fearnbach et al. 2011). This example displays the distinctive saddle patch of an adult

17 female from the Northern Resident killer whale population, identification number $=\mathrm{A} 42$ with a

18 known age of 34 years in 2014 (see Ellis et al. 2011).

20 Figure 4: Overhead image of the "I16 matriline" of Northern Resident killer whales, taken using

21 an Olympus E-PM2 camera mounted on the APH-22 hexacopter. Whales of different ages can be

22 differentiated visually and using quantitative length estimates. From top to bottom, whale

23 identifications, ages and length estimates ${ }^{*}$ are: I106 = 10yrs, 4.8m; I129 = 5yrs, 3.4m; I051=

$2428 y r s, 5.4 \mathrm{~m} ; \mathrm{I} 144=0-1 \mathrm{yrs}, 2.6 \mathrm{~m} ; \mathrm{I} 1098=12 \mathrm{yrs}, 5.1 \mathrm{~m} ; \mathrm{I} 016=45 \mathrm{yrs}, 5.8 \mathrm{~m}, \mathrm{I} 128=5 \mathrm{yrs}, 3.9 \mathrm{~m}$. 
1 Age data from Ellis et al. (2011) and Jared Towers (personal communication) *Note, the best

2 length estimates for these individual whales may change as more images are examined. 
1 Figure 1

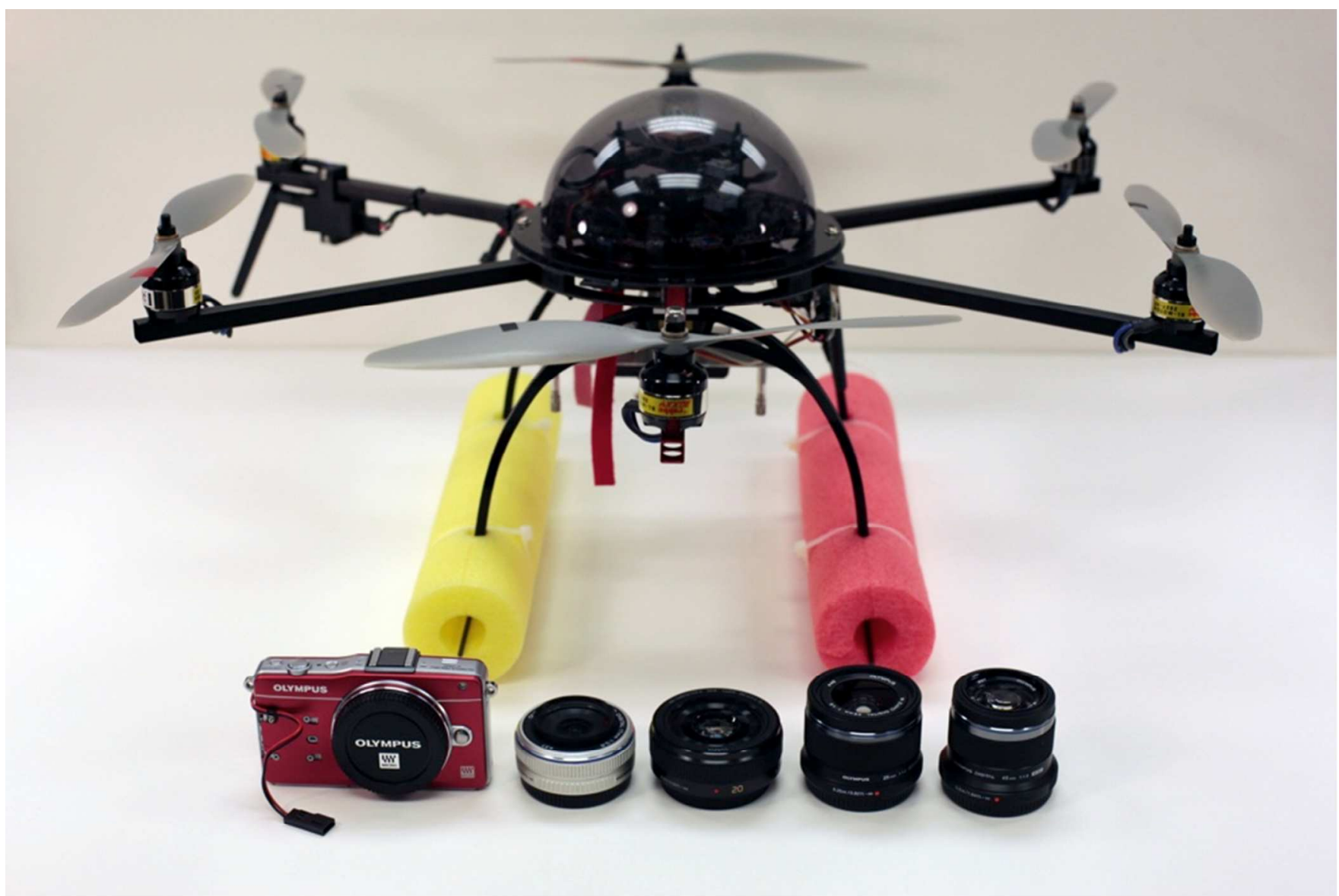

3 


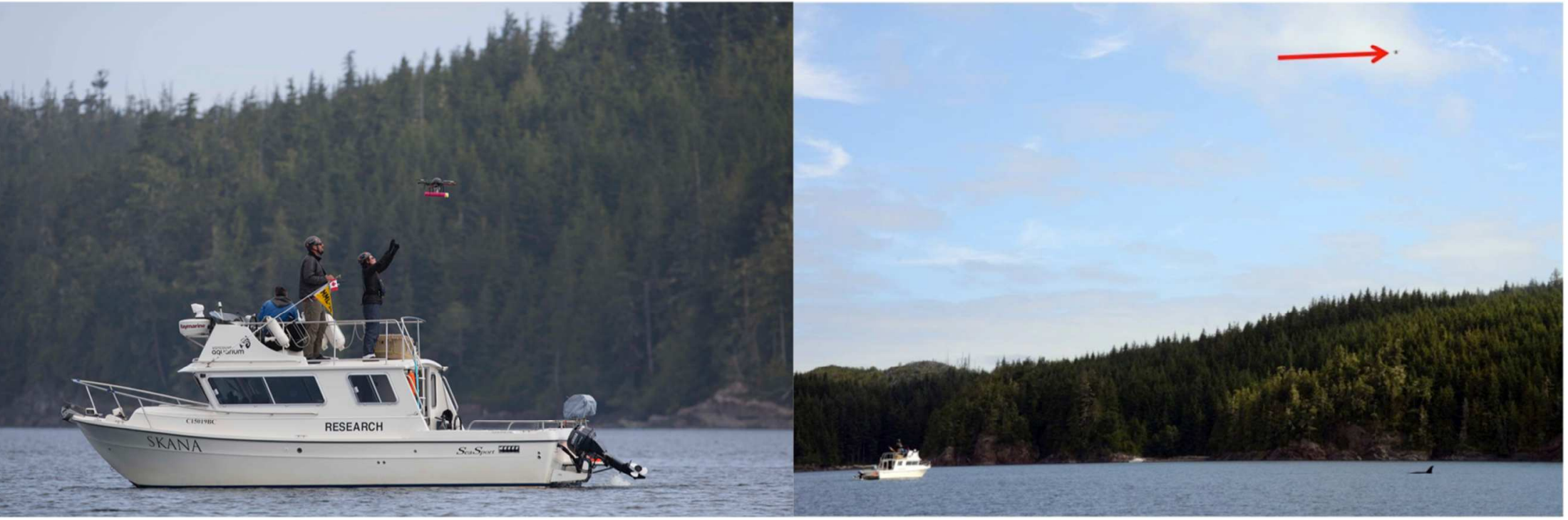


2 Figure 3

3

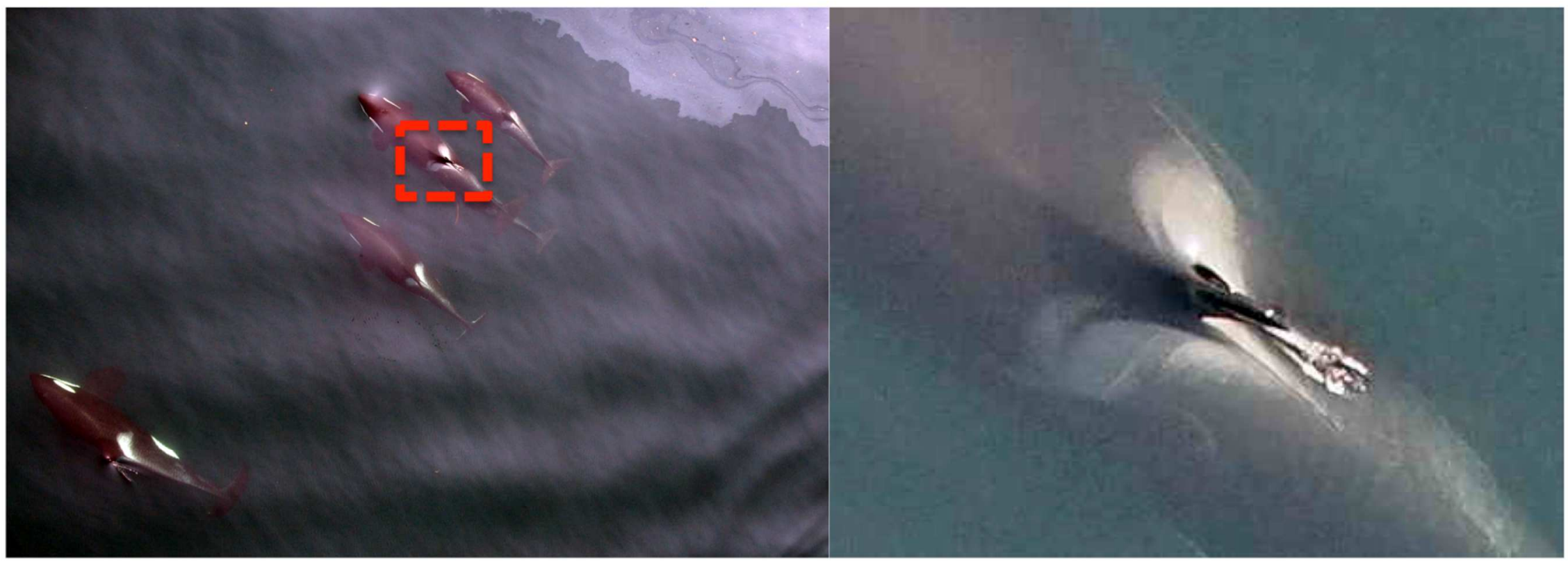

4

5

6

7

8

9 


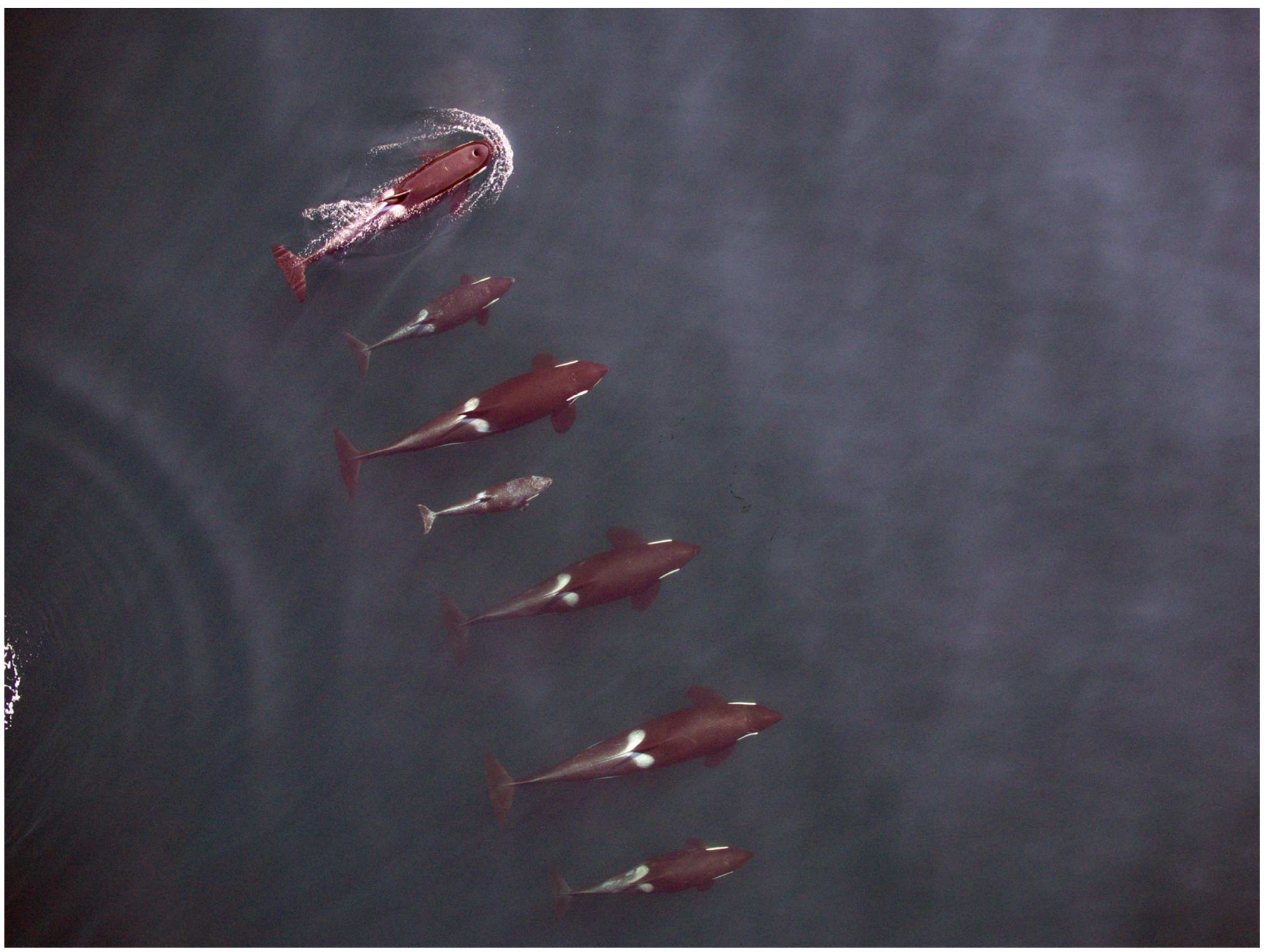

